\title{
Aspectos do romance bistórico em Erico Verissimo
}

Pedro Brum Santos | PPGL/UFSM

Resumo: A verificação de $\mathrm{O}$ continente pela ótica do romance histórico permite perceber modos através dos quais Erico Veríssimo incorporou definitivamente tal sistemática a suas composições. O cruzamento entre universo ficcional e eventos históricos conduz a inflexões a respeito da História que, em decorrência da maneira como são preparadas, surgem com naturalidade no universo narrativo.

Palavras-chave: ficção, história, sociedade.

Nos primeiros romances de Erico Verissimo - Clarissa, Caminhos cruzados, Música ao longe, os protagonistas acham-se às voltas com um passado em franca decadência - a tradição agrária do Rio Grande do Sul. Questões políticas e econômicas geram mudanças sociais e os descendentes empobrecidos buscam a cidade grande. Ao mudarem para um cenário mais amplo e complexo, distanciam-se da tradição autoritária e patriarcal de suas gêneses familiares. O modelo que passam a perseguir é o de uma democracia de pendor socializante, ideal que algumas vezes cai num pacifismo algo romântico.

Embora reconhecendo as limitações desse seu pacifismo para a realização literária - posto que a narrativa ficcional vive mesmo é do antagônico, da crise, da falta de solução - Verissimo insiste no modelo, de 
modo a reproduzir na ficção convicções pessoais que apontam para um humanismo democrático - de resto, posição difícil de sustentar em um tempo que cobrava a intervenção do intelectual frente a tudo: política, religião, moral, costumes. O autor ouviu muitas críticas pelo fato de enfrentar esses questionamentos sem radicalizar posições. Em O resto é silêncio, livro de 43, chegou mesmo a ironizar os comentaristas que denunciavam a inconsistência do mundo cor-de-rosa de suas obras: "Se ao menos Roberto fosse uma personagem dum romance teu, tu podias mudar os pensamentos dele. Não... o melhor seria mudares o mundo, escreveres um mundo belo e justo, um mundo em que eu e ele e todos pudéssemos ser felizes" (VERISSIMO, 1997, p. 308) - insiste Nora com o pai, o escritor Tônio Santiago, um dos protagonistas dessa obra e espécie de alter-ego do autor.

Em todo caso, àquela altura, o modelo da solução pacífica parecia esgotado. Verissimo confessaria que as críticas que se seguiram à publicação de Saga, em 40, firmaram-lhe essa convicção. O pacifismo ficava cada vez mais difícil de sustentar em um mundo fracionado por antagonismos belicosos. A união entre Vasco e Clarissa, no desfecho deste livro de 40, desde logo foi apontada como uma solução pouco convincente. Não estava de acordo com o comportamento pregresso das personagens, sobretudo com o espírito aventureiro de Vasco.

O projeto de O tempo e o vento, lançado a partir de 49, é fruto, portanto, de um autor bastante amadurecido. Verissimo já havia "arriscado" o suficiente. Por isso mesmo, a partir daí e até seus últimos livros, sem abandonar a convicção humanista, que continua embalando muitas de suas personagens, evita a solução fácil, problematiza os desfechos, trata de criaturas que se enredam na engrenagem social e terminam por mergulhar numa crise aparentemente sem volta.

Um fator decisivo dessa perspectiva problematizante é o uso recorrente de recursos que podem ser classificados na ordem da ficção histórica. O tempo e o vento, também por esse aspecto, ocupa posição central no conjunto da obra, visto que a preocupação com as referências históricas, já presente em produções anteriores, torna-se mais constante e nuclear a partir da trilogia iniciada no final dos anos 40.

O romance histórico, segundo a caracterização consagrada de Georg Lukács (1976), não necessita reproduzir diretamente feitos e personagens decalcados de registros do mundo empírico. Tomando como exemplo introdutório do gênero as produções de Walter Scott, Lukács lembra que nas obras 
que o autor escocês publicou no século XIX a reprodução de feitos registrados pela historiografia aparecem como pano-de-fundo. O que conta para a caracterização do romance histórico - e isso se encontra em Scott - é uma resposta que esse tipo de obra apresenta frente a questões históricas, algo que é feito através do torneio de ações nas quais são fixadas literariamente etapas da História.

A verificação de O tempo e o vento pela ótica do romance histórico permite perceber como Erico Veríssimo incorporou definitivamente tal sistemática a suas composições. Em linhas gerais, sua proposta tem em conta produzir um cruzamento entre o entrecho ficcional e eventos históricos, de modo que, no universo diegético as inflexões a respeito da História surjam com naturalidade para além dos fatos e das personagens históricas eventualmente referenciados.

Para efeito de verificação tomemos O continente. Ali, a revolução federalista de 93 serve como um leitmotiv para o desencadeamento das ações. Os episódios, seriados segundo o título de "O Sobrado", compõem seis partes espalhadas pelos dois volumes e situam-se em junho de 1895, data que coincide, no âmbito da História, com o término da revolução federalista.

No romance, a habitação encontra-se cercada pelas forças legalistas, que aparecem como vitoriosas sobre o poder político republicano de Santa Fé, liderado pelos Cambarás. Dentro da fortaleza, em condições precárias causadas pelo isolamento, resistem os representantes acuados: Licurgo, o chefe político deposto, alguns fiéis seguidores e os familiares. À medida que o leitor vai se situando em relação às personagens que se encontram no Sobrado, conhece, nos capítulos circundantes, dados de outras personagens e detalhes de outros episódios que se ligam a esses nucleares.

Além da imagem da casa - o sobrado - o autor utiliza-se de referências da natureza - sobretudo da alusão ao vento - com o fito de integrar as personagens e as ações a âmbitos cada vez mais amplos da trama e da História. Esse procedimento de integração permite uma mistura entre espaço doméstico e palco de guerra, do mesmo modo que justifica a referência ao vento como marca de tempo - numa perspectiva que conduz do particular para o geral, da parte para o conjunto, da definição de detalhes às imagenssíntese, nas quais se incluem os títulos das partes e do todo.

Assim, do mesmo modo em que se passa da casa para a guerra e do vento para o tempo, a História - guerra civil - integra-se à história - fábula. Os conflitos experimentados por Licurgo, como chefe político e pai de família, num certo nível, possuem uma lógica ficcional. Dentro dessa lógica, tais conflitos 
interagem com a queixa das mulheres - Alice, sua esposa, e Maria Valéria, a cunhada, para ficar no âmbito do sobrado.

Para além do círculo de casa - e ainda no espectro romanesco os cruzamentos se ampliam, chamando para o diálogo a memória de Ana Terra, Capitão Rodrigo, Luzia - os antepassados de Licurgo e de outros ocupantes da casa. Esses são flagrados em distintas épocas, tanto pelos recuos do tempo da narrativa como pela sobrevivência de personagens que, ao modo da velha Bibiana, avó de Licurgo, são remanescentes de outras épocas. Desse modo, novas imagens vão se formando na teia de relações aberta pelos trechos que preenchem os espaços entre as diferentes focalizações sobre o sobrado. Além de funcionarem como referências ficcionais, essas imagens vão colocando em diálogo recortes históricos diversos. De 93, retrocede-se a episódios do povoamento do solo sulino, à época das missões jesuíticas e à revolução farroupilha, para citar três declinações expressivas.

Os diferentes níveis de representação, tal como estão dispostos em O Continente - e, de resto, ao longo de todo O tempo e o vento - exigem que o leitor vá montando a história, como se juntasse as peças de um quebracabeça. O procedimento, que é próprio dos grandes romances, fica reforçado pela utilização que Verissimo faz do contraponto, técnica consagrada pelo escritor inglês Aldous Huxley, em romance de 28, no qual aprofunda o uso da composição fracionada da história, cujos pontos, disseminados pelo todo, são ampliados passo-a-passo. A essa altura podemos afirmar que o cruzamento entre entrecho ficcional e eventos históricos interfere mesmo na estrutura das obras em questão, posto que é decisivo para as dotações de tempo, espaço e seqüenciação dessas narrativas.

Um outro aspecto importante que resulta da elaboração da matéria histórica em O tempo e o vento é a força reflexiva que a ficção produz sobre os eventos tomados da historiografia. Da perspectiva do arranjo ficcional, a escolha da revolução federalista como tópico de partida de O continente - e, de resto, da própria trilogia, considerando-se que se trata do volume inaugural - reveste-se de particular significado. Na história do Rio Grande do Sul esse é um conflito essencial, pois significa a passagem da antiga ordem institucional, arranjada com os acordos imperiais que puseram fim à revolução farroupilha, à ordem republicana, assentada no ideal positivista de Júlio de Castilhos.

Registrado na história como um embate de contornos bárbaros, com fartos registros de degolas, humilhações e massacres, aos quais não escaparam 
velhos, mulheres e crianças, a revolução de 93 tornou a envolver inocentes nas contendas da elite rio-grandense. Na oportunidade, o confronto foi entre os federalistas, chamados maragatos, simpáticos ao parlamentarismo monárquico e chefiados por Gaspar Silveira Martins e os republicanos, ditos pica-paus ou chimangos, que obedeciam à chefia de Júlio de Castilhos.

O arranjo ficcional que Verissimo procede em relação a esse evento histórico, logo na abertura de O tempo e o vento, garante a visão da história que se alarga pelos demais volumes da trilogia. Ao integrar os fatos da realidade contingente ao universo diegético o autor sugere que os registros da História sejam recuperados do congelamento do passado para a multiplicidade viva do presente. Em outras palavras, com a transposição da revolta federalista para a ficção, integrando diferentes planos narrativos, Verissimo, tal como faz em $O$ continente, desveste o episódio histórico de seu sentido apriorístico e deixa-o à mercê da trama ficcional. Cabe, então, aos agentes ficcionais expressarem opiniões que, embora às vezes sejam contraditórias entre si, por isso mesmo, colocam para o leitor questionamentos que mais dizem respeito à época de produção da obra do que propriamente ao episódio retratado. A mesma lógica vale para outras referências que ocupam posição de destaque em O tempo e o vento, como são os casos da república positivista rio-grandense e da era Vargas, que predominam em O retrato e em O arquipélago.

No caso de O continente, que estamos examinando, a revolução federalista transforma-se no centro gerador em torno do qual as personagens, envolvidas no conflito, em lugar de protagonizarem cenas de enfrentamentos bélicos, refletem sobre a inutilidade das situações a que estão submetidas. $O$ velho Florêncio Terra, por exemplo, sogro de Licurgo, em meio aos silêncios do sobrado cercado, registra:

Eu tenho quase sessenta e cinco. Já vi outras guerras. Tudo isso passa. A revolução termina, os federalistas e os republicanos ficam alguns meses ou anos um pouco estranhos, mas o tempo tem muita força. Um dia se encontram, fazem as pazes, esquecem tudo (VERISSIMO, 2004, p. 11).

Os aspectos destacados por Florêncio transcendem a Revolução de 93, embora neles não se deva desprezar o quanto isso encerra de crítica sobre a tradição heróica e brava do Rio Grande do Sul. Mas acima disso, a digressão de Florêncio Terra aponta para uma dimensão hedonística da História. Esta é traduzida 
pelo princípio de que, como o tempo a tudo consome, o verdadeiro sentido da ação humana está em canalizar as energias em ações agradáveis, que sejam ao mesmo tempo simples e compensadoras e que, acima de tudo, signifiquem fontes de prazer.

Fandango, o velho e alegre contador de histórias, igualmente submetido ao cerco do Sobrado, exprime seus sentimentos exatamente nesses termos:

\begin{abstract}
Curgo vive dizendo que os maragatos são bandidos. Mas qual! Todo mundo sabe que há gente boa e gente ruim dos dois lados. (...) [a guerra é] uma sangueira braba, uma perda horrível de vidas, de dinheiro e de tempo! E no entanto o mundo tem tanta coisa gostosa! Mulher bonita, cavalo bom, baile, churrasco, mate amargo... Laranja madura, melancia fresca, uma guampa de leite gordo ainda quente dos úberes da vaca... Uma boa prosa perto do fogo... Uma pescaria, uma caçada, uma sesta debaixo dum umbu... Tanta coisa! (Idem, p. 287).
\end{abstract}

Reflexões como as de Florêncio e Fandango - e aqui é mais uma vez o fato histórico ganhando expressão particular pelo ponto de vista das personagens - reforçam a ilustração sobre o alcance do romance histórico em Erico Verissimo. Distanciando-se da pura e simples revisão do passado, o autor busca, a partir desse, montar o seu projeto ficcional de modo que, de acordo com a tradição do romance histórico, os episódios referenciados sirvam para que o leitor vá adiante e atualize, não apenas os fatos, mas questões candentes que eles ainda sejam capazes de suscitar.

Abstract: The verification of $\mathrm{O}$ continente for the optics of the historical novel allows to perceive ways through the which Erico Verissimo definitively incorporated such systematic its compositions. The crossing between the fiction's universe and historical events leads the inflections regarding the History that, in result in the way as are prepared, appear with naturalness in the narrative universe.

Key words: fiction, bistory, society. 
Disponivel em: http://www.letras.ufmg.br/poslit

Referências Bibliográficas

CHAVES, Flavio Loureiro. Erico Veríssimo: realismo e sociedade. Porto Alegre: Mercado Aberto, 1981.

LUKÁCS, Georg. La novela histórica. Barcelona: Grijalbo, 1976.

VERISSIMO, Erico. O resto é silêncio. Rio de Janeiro: Globo, 1997.

VERISSIMO, Erico. O tempo e o vento. São Paulo: Companhia das Letras, 2004.7 v. 